\title{
O UNIVERSO DO SAMBA E O ENSINO DA HISTÓRIA E CULTURA AFRICANA E AFRO-BRASILEIRA
}

\author{
THE SAMBA UNIVERSE AND THE TEACHING OF AFRICAN AND AF- \\ RO-BRAZILIANHISTORY AND CULTURE \\ EL UNIVERSO DEL SAMBA Y LA ENSEÑANZA DE LA HISTORIA Y CUL- \\ TURA AFRICANA Y AFRO-BRASILEÑA
}

Gustavo Arantes Camargo ${ }^{1}$

Cláudia Foganholi ${ }^{2}$

\section{RESUMO}

Compreendemos o universo do samba como as narrativas das relações que constituem a história do samba, na perspectiva das pessoas negras no Brasil. O reconhecimento dessas histórias, contadas em sons, versos e movimentos são fundamentais para a compreensão da formação da sociedade brasileira e para a desconstrução de preconceitos e desqualificações acerca da história, cultura e identidade da população afro-brasileira. Articulando esses conhecimentos com o Parecer n. 003/2004 do Conselho Nacional de Educação, que regulamenta a alteração trazida à Lei 9.394/96 de Diretrizes e Bases da Educação Nacional pela Lei 10.639/03, este artigo tem como objetivo propor uma reflexão sobre o universo do samba em sua potencialidade para o Ensino da História e Cultura Africana e Afro-brasileira na escola. Considerando a riqueza e abundância da produção simbólica que compõe o samba, é possível atentar para os modos de ser e viver, educar e educar-se no contexto deste universo que possam nos auxiliar a pensar e apreender sobre a Educação das Relações Étnico-raciais no país.

PALAVRAS-CHAVE: Lei 10.639/03, samba, educação e relações étnico-raciais.

1 Professor Adjunto de Filosofia da Universidade Federal do Rio de Janeiro - Campus Macaé e do Instituto de Biodiversidade e Sustentabilidade NUPEM/UFRJ - gustavonhani@gmail.com

2 Professora Adjunta do Instituto de Educação Física da Universidade Federal Fluminense -foganholi@ hotmail.com 


\section{ABSTRACT}

We understand the universe of samba as the narratives of the relations that constitute the history of samba, from the perspective of black people in Brazil. The recognition of these stories, told in sou$n d s$, verses and movements are fundamental for understanding the formation of Brazilian society and for the deconstruction of prejudices and disqualifications about the history, culture and identity of the Afro-Brazilian population. Articulating this knowledge with the Opinion Report number 003/2004 of the National Education Council (Conselho Nacional de Educação), which regulates the change brought to the Law number 9.394/96 of the Education Law (Diretrizes e Bases da Educação Nacional) for the Law number 10.639/03, this article aims to propose the reflection on the universe of samba in its potentiality for the Teaching African and Afro-Brazilian History and Culture in school. Considering the richness and abundance of the symbolic production that composes samba, it is possible to pay attention to the ways of being and living, to educate and to educate oneself in the context of this universe that can help us to think and learn about the Education of Ethnic-racial Relations in the country.

KEYWORDS: Law number 10.639/03, samba, education, race relations.

\section{RESUMEN}

Comprendemos el universo del samba como las narrativas de las relaciones que constituyen la historia del samba, en la perspectiva de las personas negras en Brasil. El reconocimiento de esas historias, contadas con sonidos, versos y movimientos son fundamentales para la comprensión de la formación de la sociedad brasileña y para la deconstrucción de prejuicios y descalificaciones acerca de la historia, cultura e identidad de la población afro-brasileña. Articulando estos conocimientos con el Parecer $n^{\circ}$. 003/2004 do Conselho Nacional de Educação, que regula la modificación de la Ley 9.394/96 de Directrices e Bases da Educación Nacional por la Ley 10.639/03, este artículo tiene como objetivo proponer la reflexión sobre el universo del samba en su potencialidad para la Enseñanza de la Historia y Cultura Africana y Afro-brasileña en la escuela. Considerando la riqueza y abundancia de la producción simbólica que compone el samba, es posible atender a los modos de ser y vivir, educar y educarse en el contexto de este universo, lo que puede ayudarnos a pensar y aprender sobre la Educación de las Relaciones Étnico-raciales en el país.

PALABRAS-CLAVE: Ley 10.639 / 03, samba, educación, relaciones étnico-raciales.

"Eu digo e até posso afirmar, vive melhor quem samba".

(CANDEIA, 1970) 
O objetivo deste artigo é propor uma reflexão sobre o universo do samba em sua potencialidade para o ensino da história e cultura africana e afro-brasileira na escola. Compreendemos o universo do samba como uma manifestação da cultura popular, de origem afro-brasileira, constituído pela história e pelos modos de ser, pensar e viver dos descendentes de africanos no Brasil. Composto, portanto, entre sons, versos e movimentos, pelas narrativas das relações entre as pessoas e entre estas e o mundo na perspectiva das pessoas negras, o samba nos permite conhecer a história e a cultura dessa parcela da população a partir de suas experiências.

Desta forma, a proposta de abordagem do universo do samba na escola não se restringe à inserção do samba como um conteúdo programático nos componentes curriculares, mas visa ampliar a compreensão deste universo atentando para sua possibilidade de sulear ${ }^{3}$ processos educativos que possam “[...] desfazer mentalidade racista e discriminadora secular, superando o etnocentrismo europeu, reestruturando relações étnico-raciais e sociais, desalienando processos pedagógicos" (BRASIL, 2004, p.6).

Para além da produção simbólica e dos registros históricos presentes no universo do samba, é possível atentar para os modos de ser e viver, educar e educar-se no contexto deste universo que possam nos auxiliar a pensar e apreender sobre a Educação das Relações Étnico-raciais no Brasil. Como expressa o samba "Viver", composto por Candeia e que nos serve de epígrafe:

Lá lá ia lá ia, lá lá ia lá ia lá

Eu digo e até posso afirmar, vive melhor quem samba

Vou pela rua cantando e o clarão da lua vem ornamentar Sim, vou levando alegria pra dona Tristeza alegre ficar Abra a janela do peito e deixe meu samba passar Samba não tem preconceito e já vai se libertar

A liberdade dos prantos e dos desencantos que a vida nos deu A liberdade que canto é amor, é esperança pra quem já sofreu Cada qual que olhar para trás verá que sempre há uma razão de viver Quem guerreia pela paz, a verdadeira paz nunca há de ter.

Cantem todos como eu faço, perdoem os fracassos

A vida é tão curta.

Enquanto se iluda, se samba também

Noite fria enluarada, fim de madrugada

Feliz vou cantando, cantando alegria que o samba contém

(CANDEIA, 1970).

O samba pode ser entendido, segundo Lopes (2003, p.11), como "gênero matriz da música popular brasileira e sua corrente principal". Entretanto, ainda nos impressiona como pouco

3 Sulear é um termo usado por Paulo Feire (1997) que chama atenção para a conotação ideológica do termo nortear, comumente utilizado para identificar a referência ao norte como orientação correta. 
ou nada se fala sobre o samba como tema curricular. Tal carência é tão mais assustadora quando nos damos conta de que o Samba deveria ser matéria regular nas nossas escolas, assuntos correntes em nossa academia - por corresponder ao que o país produziu e produz de melhor, e de mais original, entre suas criações líteromusicais (MUSSA, 2017, p. 9).

Em tese de doutoramento, Costa (2001, p. 9) defende que o discurso lítero-musical brasileiro pode fazer o papel do discurso constituinte, a partir da compreensão de Dominique Maingueneau, "como o discurso que: dá sentido aos atos da coletividade, consistindo numa forma de vida articuladora da consciência coletiva a indicar modos de sentir, de pensar e de interpretar os fatos socioculturais [...]".

Neste sentido, apontando para o parentesco entre o discurso lítero-musical e o discurso literário, embora não se confundam, Costa (2001, p. 465) afirma que "o fato de o discurso lítero-musical conter, além do texto, a música, leva à necessidade de se considerar não apenas a dimensão do narrado ou descrito (em oposição ao vivido), mas também a do cantado (em oposição ao mudo, ou apenas falado)”.

Não se tratando de defender a escolarização do samba ou de adaptá-lo aos moldes tradicionais e disciplinares dos sistemas de ensino, nossa proposta é refletir sobre como o samba pode contribuir com o estudo da história e cultura afro-brasileira, conforme possibilidade mencionada por Lopes e Simas (2017, p. 80) ao destacarem que "o ensino da história do samba para crianças, em seus aspectos sociais e culturais, nas escolas de ensino fundamental e médio das redes públicas e privadas, ganhou impulso com a Lei 10.639/03 [...].”

Ao regulamentar a alteração trazida à Lei 9.394/96 de Diretrizes e Bases da Educação Nacional pela Lei 10.639/03, que estabelece a obrigatoriedade do ensino de História e Cultura Afro-Brasileira e Africana na Educação Básica, o Parecer n. 003/2004 do Conselho Nacional de Educação indica que, diante do engajamento no combate ao racismo e às desigualdades sociais e raciais, a atuação da escola, de professoras e professores, deve ser fundamentada na mudança destas posturas e "[...] não pode ficar reduzida a palavras e a raciocínios desvinculados da experiência de ser inferiorizados vivida pelos negros, tampouco das baixas classificações que lhe são atribuídas nas escalas de desigualdades sociais, econômicas, educativas e políticas" (BRASIL, 2004, p.6).

As Leis 10.639/03 e 11.645/08 escancararam a grande lacuna existente em nossos sistemas de ensino em relação ao ensino da história e cultura afro-brasileiras e indígenas como povos constituintes da nação brasileira, trazendo para o centro do debate escolar e universitário a necessidade de ações afirmativas, reconhecimento e valorização da história e cultura desses povos, fortalecendo a identidade e formando cidadãos orgulhosos de seu pertencimento a um grupo étnico racial (BRASIL, 2004, p. 2). Para tanto, é preciso reconhecer o papel positivo desempenhado por esses grupos na cultura nacional. 
O combate ao racismo e ao racismo epistêmico é, pois, um problema também da escola e da universidade, visto que essas têm a tarefa de promover a igualdade de condições de vida e de cidadania. O racismo epistêmico, segundo Grosfoguel (2011, p. 343), apresenta-se quando “se considera o 'ocidente' como a única tradição de pensamento legítima capaz de produzir conhecimento e como a única com acesso à 'universalidade', à 'racionalidade' e à 'verdade'. $\mathrm{O}$ racismo/sexismo epistêmico vê o conhecimento 'não ocidental' como inferior ao conhecimento 'ocidental'"'4. O autor explicita que a pretensão de universalidade e neutralidade do conhecimento por parte do ocidente na verdade tem cor e gênero, trata-se de uma epistemologia branca e masculina na base de sustentação do projeto colonial sem o qual não se explica o surgimento e o desenvolvimento do capitalismo.

Esse racismo epistêmico se expressa, como estamos apontando, na ocultação e não reconhecimento da história da população negra africana na diáspora brasileira e de seus descendentes, assim como pela desvalorização de sua cultura, entendida como algo menor ou sem grandeza. Neste contexto, se o samba é o gênero matriz e a maior criação da música brasileira, sua ausência dos espaços formais de ensino é a expressão desse racismo que aqui se denuncia. Do ponto de vista da Educação, acreditamos que o Estado deve atuar no sentido de dirimir esse racismo. Sem essa intervenção, vemos que a situação de desigualdade tende a se perpetuar.

A partir das ideias de Frantz Fanon, Simas (2016, p. 3) diz que

[...] o racismo herdado do colonialismo se manifesta explicitamente - e com mais furor - a partir de características físicas, mas não apenas aí. A discriminação também se estabelece a partir da inferiorização de bens simbólicos daqueles a quem o colonialismo tenta submeter: crenças, danças, comidas, visões de mundo, formas de celebrar a vida, enterrar os mortos, educar as crianças etc.

Fanon (1980, p.36) explicita que "esse racismo que se pretende racional, individual, determinado, genotípico e fenotípico, transforma-se em racismo cultural. O objeto do racismo já não é o homem particular, mas uma certa forma de existir". O combate a esse racismo cultural se comunica diretamente com a lei em questão, quando destaca em seu parecer que "o ensino de cultura afro-brasileira destacará o jeito próprio de ser, viver e pensar manifestado tanto no dia a dia, quanto em celebrações como congadas, moçambiques, ensaios, maracatus, rodas de samba, entre outras". (BRASIL, 2004, p. 12)

Neste sentido, pensar o samba significa pensar a construção de práticas pedagógicas brasileiras e afro-brasileiras que possam se constituir como "pedagogias de combate ao racismo e a discriminações elaboradas com o objetivo de educação das relações étnico/raciais positivas" que

4 Tradução nossa. 
têm como objetivo fortalecer entre os negros e despertar entre os brancos a consciência negra. Entre os negros, poderão oferecer conhecimentos e segurança para orgulharem-se da sua origem africana; para os brancos, poderão permitir que identifiquem as influências, a contribuição, a participação e a importância da história e da cultura dos negros no seu jeito de ser, viver, de se relacionar com as outras pessoas, notadamente as negras (BRASIL, 2004. p. 7).

A ideia cantada por Noel Rosa (ROSA; VADICO, 1933) de que "batuque é um privilégio/ ninguém aprende samba no colégio" nos soa mais como uma autoafirmação do samba e do sambista, isto é, da cultura do samba, do que uma defesa de seu não estudo formal. Nessa perspectiva, acreditamos que o samba, assim como todas as expressões das culturas populares brasileiras tais como capoeira, jongo, etc., não se aprende no colégio. As culturas populares são por si só verdadeiros sistemas de ensino. Só se aprende capoeira participando da capoeira, dos grupos, tornando-se discípulo de um Mestre, assim como o jongo se aprende no seio das comunidades tradicionais e é lá nas madrugadas dos quilombos que o tambor toca e o jongo se faz, com Mestras e Mestres. Um Mestre de bateria de Escola de Samba não é alguém que se formou na Escola de Música de uma Universidade famosa, e sim aquele que viveu a cultura do samba, dentro de sua Escola de Samba. Não podemos crer que algum sistema formal de ensino, instituído ou controlado pelo Estado, seria capaz de realizar esse papel. Aliás, a tentativa de institucionalização das culturas populares se mostra, em geral, como mecanismo de controle e domesticação das mesmas. Como exemplo, podemos citar todas as vezes em que se tentou impor à capoeira que seus professores tivessem, para ter o direito de dar aula, o diploma de Ensino Superior em Educação Física e registro no Conselho Profissional ${ }^{5}$. Tal obrigatoriedade excluiria os verdadeiros Mestres de Capoeira do ensino e perpetuação de sua arte, assim como validaria não-capoeiristas como professores de capoeira. Essa situação nos obriga a tomar muito cuidado sempre que relacionamos culturas populares e sistemas formais de ensino.

Assim, o ponto central de nossa argumentação que envolve samba e educação é o desejo de "reconhecimento e igual valorização das raízes africanas da nação brasileira" (BRASIL, 2004, p.11) nos ambientes escolares.

Silva e Noguera (2015, p. 23), ao discorrerem sobre o samba no cenário pós-abolição da cidade do Rio de Janeiro, afirmam que

o samba é mais do que um estilo musical. É uma estética de vida. Ele tem grande importância na formação e na afirmação dos grupos étnicos na cidade, sendo relacionado à ideia de pertencimento em relação a um grupo ou a um lugar simbólico específico.

5 A livre atuação de Mestres e Mestras de capoeira tem sido constantemente ameaçada desde meados de 1990, quando o Conselho Nacional de Educação Física (CONEF) e seus órgãos regionais, por meio da Lei $n^{\circ}$ 9.696/98, entraram na disputa pela regulamentação do ensino da capoeira. 
Tal compreensão nos impele a refletir sobre a relevância de, a partir do samba, reconhecer e reviver com as novas gerações dentro da escola a memória de uma longa história de resistência dos diversos grupos de pessoas afro-brasileiras que, em todo o território nacional, compuseram, tocaram ou foram tocados por essa história.

Neste sentido, alinhado com as Diretrizes Curriculares Nacionais para a Educação das Relações Étnico-Raciais e para o Ensino de História e Cultura Afro-Brasileira e Africana, este artigo pretende apontar alguns elementos do universo do samba que possam servir de subsídios para a construção de processos educativos antirracistas e de uma escola mais justa e equânime no que se refere ao reconhecimento e à valorização da história, cultura e identidade da população afro-brasileira. Para atingir este objetivo, propomos, como um caminho possível, ouvir o que as vozes dos sambistas nos contam que nos ajudem a dialogar com os três princípios propostos pelo parecer Parecer n. 003/2004 do CNE (BRASIL, 2004, p.9) como referências para a condução de ações para a Educação das Relações Étnico-raciais em todos os níveis de ensino. Estes princípios: 1) Consciência política e histórica da diversidade; 2) Fortalecimento de identidades e de direitos; 3) Ações educativas de combate ao racismo e a discriminações. Esses serão articulados, a seguir, com alguns dentre tantos conhecimentos registrados e produzidos sobre o universo do samba, compreendendo que "reconhecer é também valorizar, divulgar e respeitar os processos históricos de resistência negra desencadeados pelos africanos escravizados no Brasil e por seus descendentes na contemporaneidade, desde as formas individuais até as coletivas" (BRASIL, 2004, p. 4).

\section{As histórias do samba e do Brasil}

A importância do samba no campo da Educação das Relações Étnico-raciais pode ser apreciada quando o entendemos como estratégia de resistência da população negra no Brasil em relação a várias circunstâncias históricas como o crescimento da economia cafeeira no Sudeste do país ao longo do século XIX, o fim do tráfico negreiro a partir de 1850 e as políticas públicas de exclusão e perseguição à população negra no Rio de Janeiro. Para Lopes, Noguera e Moraes (20015, p. 17), o samba se constitui como parceria fundamental para uma agenda filosófica afro-perspectivista, "porque o samba é um exercício de resistência negra. A história do samba brasileiro foi a reunião de mulheres e homens que pensavam e criavam condições de intervenção a partir da música cantada, dançada em eventos que primavam pela fartura de comidas e bebidas".

Durante todo o período colonial, a economia brasileira foi centralmente agrária e escravista. No início da década de 1830, o café assumiu a liderança das exportações do país, ultrapassando o açúcar, o algodão e o fumo (ABREU; LAGO, 2010). Essa mudança produziu uma transformação no eixo dinâmico da economia do país, uma vez que o plantio de café ocorria no Sudeste, enquanto os produtos anteriores tinham sua produção concentrada no Nordeste, o que 
causa também um deslocamento geográfico da população escravizada:

Na primeira metade do século XIX, a importação de escravos para a "região cafeeira" respondeu, possivelmente, por mais de $2 / 3$ das importações totais de escravos no Brasil, que alcançou aproximadamente um total de 1,3 milhões de pessoas (ABREU; LAGO, 2010, p. 13).

O Cais do Valongo, hoje sítio arqueológico da cidade do Rio de Janeiro, redescoberto durante obras na zona portuária em 2011, foi um dos portos que mais recebeu povos africanos escravizados do mundo. Os africanos, principalmente Bantos trazidos da costa de Angola (MOURA, 1995, p. 60), desempenharam papel fundamental no desenvolvimento cultural do país. Segundo Lopes (2003, p. 15), os responsáveis pela criação da maioria dos folguedos de rua presentes hoje nas Américas e pela vinda de muitos instrumentos musicais do continente africano para o americano "foram certamente africanos do grande grupo etnolinguístico Banto que legaram à música brasileira as bases do samba e o amplo leque de manifestações que lhe são afins".

De acordo com Tinhorão (2010), o fim da escravidão em 1888 promoveu uma grande onda migratória de trabalhadores negros do campo para a cidade do Rio de Janeiro, capital da República do Brasil a partir de 1889, que em sua maioria eram ex-escravizados e seus descendentes que foram levados da Bahia para o Vale da Paraíba durante a expansão cafeeira. Segundo o autor, foi entre as comunidades constituídas por estes grupos, no Rio de Janeiro, que surgiu as duas maiores criações coletivas populares no Brasil: "o carnaval de rua dos ranchos e suas marchas, e o ritmo do samba” (TINHORÃO, 2010, p. 277).

Esses fatores favoreceram o surgimento de uma comunidade baiana na cidade do Rio de Janeiro e "por ação dessa comunidade nasceram os primeiros terreiros cariocas e fluminenses de candomblé e se desenvolveu o samba carioca, nascido no Rio, mas no 'território baiano' da Pequena África" (LOPES; SIMAS, 2017, p. 27). Nos terreiros, além da religião, fazia-se samba, provavelmente o samba de roda, "forma ancestral da dança do samba" (Ibidem, p.263), manifestação cultural que "[...] é a pedra fundamental do grande edifício do samba brasileiro". Assim, os autores afirmam que o samba, seus estilos, modalidades e vertentes são "nascidos a partir do estabelecimento do samba de roda baiano na cidade do Rio de Janeiro" (Ibidem, p. 16)

O reconhecimento destas e outras histórias dos povos africanos e seus descendentes no Brasil são fundamentais para a compreensão da formação da sociedade brasileira e para a desconstrução de preconceitos e desqualificações acerca da história e cultura africana e afro-brasileira. Essas histórias muitas vezes estão presentes nos versos dos sambas que compõem parte da riqueza cultural deste universo e, como propõe o princípio "Consciência política e histórica da diversidade" do Parecer 003/2004, podem nos conduzir "ao conhecimento e à valorização da história dos povos africanos e da cultura afro-brasileira na construção histórica e cultural 
brasileira" (BRASIL, 2004, p.9).

É o que podemos observar, por exemplo, na música "Kizomba, festa da raça", de Luiz Carlos da Vila, que traz em seus versos inúmeros elementos desta história e cultura que podem ser explorados nos estudos escolares direcionados para a Educação das Relações Étnico-raciais:

Valeu Zumbi

O grito forte dos Palmares

Que correu terras, céus e mares

Influenciando a Abolição

Zumbi valeu

Hoje a Vila é Kizomba

É batuque, canto e dança

Jongo e Maracatu

Vem, menininha, pra dançar o Caxambu (bis)

Ô ô nega mina

Anastácia não se deixou escravizar

Ô ô Clementina

O pagode é o partido popular

Sarcedote ergue a taça

Convocando toda a massa

Nesse evento que com graça

Gente de todas as raças

Numa mesma emoção

Esta Kizomba é nossa constituição

Que magia

Reza ageum e Orixá

Tem a força da Cultura

Tem a arte e a bravura

E um bom jogo de cintura

Faz valer seus ideais

E a beleza pura dos seus rituais

Vem a Lua de Luanda

Para iluminar a rua

Nossa sede é nossa sede

De que o Apartheid se destrua.

(VILA; RODOLPHO; JONAS, 1988)

O samba, em seu caráter lítero-musical, apresenta a recorrência de versos que, tal qual a literatura africana, em países como Angola, Moçambique, Guiné-Bissau e São Tomé e Príncipe, entre outros, é marcada pelo caráter de fortalecimento da identidade africana e pela luta de libertação de seus países. Sobretudo, em muitos poemas versam sobre a construção de uma identidade cultural e denunciam a exploração colonial. 
A exemplo disso, ao analisar a obra de Agostinho Neto, figura fundamental na luta de libertação de Angola, Silva (2012, p.3) indica em seus poemas "a incessante busca de denunciar os sofrimentos causados pela colonização portuguesa e exaltar a identidade africana". Desta forma, assim como a literatura africana nos ajuda a compreender a realidade das sociedades daquele continente, o samba constituído como expressão lítero-musical nos conta a realidade, a história e a cultura afro-brasileira.

Ao analisar as mudanças socioeconômicas no país a partir das manifestações culturais desenvolvidas pelos africanos e seus descendentes, é possível observar a presença da produção simbólica e artística africana e afrodescendente, assim como o registro da história destes grupos em todo o território nacional. Exemplo disso são os diversos registros das danças e cantos realizados pelos povos africanos e seus descendentes nos ecos do Barroco do século XVII, como na obra de Gregório de Matos, e nos relatos de danças como as chamadas fofas e lundus no século XVIII (TINHORÃO, 2010). Nestes relatos, feitos pelos colonizadores, são inúmeros os registros das manifestações culturais africanas e afro-brasileiras chamadas pejorativamente de danças dos negros escravos, danças lascivas, primitivas, indecentes, sons grotescos, entre outras denominações depreciativas. Nestes, mostra-se o preconceito e a discriminação no olhar que, alicerçando a sociedade racista, promoveram naquele período e ainda hoje influenciam a marginalização de tais práticas.

No que diz respeito à desqualificação da cultura negra, a relevância de retomarmos e compreendermos esta construção histórica é reiterada atualmente quando nos deparamos com situações nas quais a capoeira, por exemplo, é proibida no ambiente escolar por ser equivocadamente associada às religiões de origens culturais africanas. Outro exemplo, ocorrido recentemente com ampla divulgação nas redes sociais, foi o episódio em que um cantor de música sertaneja, em rede aberta de televisão, diz que o samba é música de bandido, afirmação sobre a qual se referiu posteriormente dizendo que era apenas uma brincadeira. Nestas situações, podemos constatar não apenas o desconhecimento das culturas afro-brasileiras, mas sobretudo a forte influência de uma construção histórica negativa da identidade negra no país que se perpetua há séculos nas entranhas racistas da sociedade brasileira. Por isso,

é importante tomar conhecimento da complexidade que envolve o processo de construção da identidade negra em nosso país. Processo esse, marcado por uma sociedade que, para discriminar os negros, utiliza-se tanto da desvalorização da cultura de matriz africana como dos aspectos físicos herdados pelos descendentes de africanos (BRASIL, 2004, p. 7).

Neste contexto, o desenvolvimento do princípio "Consciência política e histórica da diversidade" para guiar as ações dos sistemas de ensino como propõe a Lei 10.639/03 apresenta sua indissociabilidade dos demais princípios explicitados no Parecer acerca da referida lei, a saber: "Fortalecimento de identidades e de direitos" e "Ações educativas de combate ao racis- 
mo e a discriminações", sobre os quais tentaremos refletir adiante com o auxílio do universo do samba.

\section{O samba e a formação de laços identitários}

Ao trazer o "fortalecimento de identidades e de direitos" como princípio para implementação da Lei 10.639/03, o Parecer 003/2004 indica que o mesmo deve orientar para:

- o desencadeamento de processo de afirmação de identidades, de historicidade negada ou distorcida; - o rompimento com imagens negativas forjadas por diferentes meios de comunicação, contra os negros e os povos indígenas; [...] - a ampliação do acesso a informações sobre a diversidade da nação brasileira e sobre a recriação das identidades, provocada por relações étnico-raciais; [...] (BRASIL, 2004, p. 10).

A partir destas orientações, buscamos no universo do samba, constituído por suas músicas, mas também por sua história e origens culturais, acentuar algumas situações que nos permitem conhecer uma história da população negra no Brasil que raramente é contada nos livros didáticos. Nessa perspectiva, tentaremos adiante destacar nesta história, cantada e dançada no samba, os conhecimentos que podem favorecer o diálogo acerca do fortalecimento de identidades e de direitos das pessoas negras na escola. Em outras palavras, propomos, ao olhar para o universo do samba, tentar ouvir algo que nos ajude a compreender a construção da identidade negra e pensar estratégias de combate a injustiças e desigualdades raciais e sociais.

Iniciamos este olhar pelo momento em que, ao mesmo tempo em que o samba florescia na cidade do Rio de Janeiro entre as comunidades pobres e negras, a atuação do Estado contra estas também crescia nas políticas públicas que, de uma maneira geral, terminavam por agravar ainda mais as dificuldades que tinham para viver. Neste sentido, ao observar a história do samba, nos deparamos também com os modos de educar e educar-se em convívio, bem como as formas de resistência existentes nos momentos de opressão.

Vamos descobrir que pessoas espezinhadas, economicamente despossuídas, culturalmente desvalorizadas, mesmo vivendo situações de opressão, são capazes de reconstruir positivamente seus jeito de ser, viver, pensar, apoiados em valores próprios a seu pertencimento étnico-racial (SILVA et al., 2006), à sua condição social. São os valores de refúgio que permitiram a muitos colonizados sobreviver a toda e qualquer tentativa de aniquilação (MEMMI, 1973). Valores esses que garantiram aos africanos escravizados, arrancados de seus povos, constrangidos física e moralmente a fazer a viagem que se dizia sem retorno, viessem a edificar outros povos, os africanos da diáspora (SILVA, 2007, p. 501).

Será em um Rio de Janeiro que abrigou milhares de pessoas trazidas da África, que recebeu os negros trazidos da Bahia com o samba de roda, uma cidade e um país que negava à 
população negra direitos sociais, perseguindo-os e segregando com políticas públicas contrárias a sua inserção cidadã, que o samba, assim como os terreiros de candomblé, zungus e outras formas de organização coletiva se desenvolverá, tendo papel fundamental na constituição de laços afetivos e de confiança entre a população negra. "Florescida no contexto da opressão escravista e desenvolvendo-se em condições absolutamente adversas, a história do samba pode ser vista como uma sucessão de episódios de resistência” (LOPES; SIMAS, 2017, p. 242).

A população negra no Brasil teve que construir por si mesma as formas de sociabilidade e as estratégias de sobrevivência que garantiram sua vida na diáspora. A cultura aparece aqui como a construção autônoma de um elo entre essas pessoas e a cidade do Rio de Janeiro como o local deste encontro e construção.

A cidade é também e sobretudo produtora constante de cultura, entendida aqui como um conjunto de práticas e elaborações simbólicas definidoras e dinamizadoras de modos de vida. Nesta perspectiva, cultura não é coisa naturalmente boa ou ruim. Cultura é a maneira como um grupo cria ou reelabora formas de vida e estabelece significados complexos sobre a realidade que o cerca. As maneiras de falar, vestir, comer, rezar, punir, matar, nascer, enterrar os mortos, chorar, festejar, envelhecer, dançar, não dançar, fazer música, silenciar, gritar" (SIMAS, 2016, p. 1).

Sendo boa parte dos negros residentes na região portuária do Rio de Janeiro, nos bairros da Saúde, Gamboa, Santo Cristo, Praça Mauá, Morro da Conceição, essa região seria batizada por Heitor dos Prazeres como uma África em miniatura. Posteriormente, Roberto Moura cunhará o termo Pequena África, que é usado até hoje. Será nessa região que a maioria da população negra irá viver e se organizar, sempre a partir de suas próprias manifestações culturais. Essas não eram somente formas de encontros ou festividades, mas os terreiros de candomblé e o samba ajudaram a criar laços que permitiam a esse grupo se auxiliar e mitigar suas enormes dificuldades: foram formados verdadeiros grupos de assistência mútua e solidariedade a partir do samba. Esses laços criados culturalmente garantiram maior dignidade e reconhecimento identitário entre o povo negro no Rio de Janeiro do final do século XIX e início do XX.

Os primeiros que conseguem uma situação na capital, um lugar para morar e cultuar os orixás e uma forma de trabalho, não hesitam em fornecer comida e moradia aos que vão chegando, o que permitiu um fluxo migratório regular até a passagem do século, garantindo uma forte presença dos baianos no Rio de Janeiro (MOURA, 1995, p.121).

A Pequena África ainda cresceu a partir principalmente do que ficou conhecido como bota-abaixo, um conjunto de reformas urbanas promovidas pelo então prefeito Pereira Passos, em 1904. Reforma cuja medida principal se deu pela derrubada de prédios, cortiços e casas de cômodo na região central da cidade para a construção da que hoje é conhecida como Av. Rio Branco. Com elas, os moradores pobres são forçadamente excluídos do centro da cidade e boa 
parte dos moradores se deslocaram para locais perto do Campo de Santana até a Cidade Nova, ampliando a abrangência da Pequena África. As ocupações dos morros próximos, como o da Providência, do São Carlos e da Mangueira também acontecem em virtude de tais reformas, dando início ao povoamento dos morros no Rio de Janeiro e criando as primeiras favelas. Por fim, a linha de trem chegava agora até Oswaldo Cruz, propiciando também a ocupação das periferias.

A Saúde, onde se concentrava grande parte da colônia baiana, integrados os homens como estivadores no porto, seria também afetada pelas reformas, fazendo com que muitos, juntamente com seus novos parceiros arrebanhados pela situação comum, fossem procurar moradia pelas ruas da Cidade Nova, além do Campo de Santana, ou para os subúrbios e, logo depois, nos morros em torno do Centro (MOURA, 1995, p. 76).

Para Simas (2016, p. 5), a ideia de uma Pequena África nos arredores da Praça Onze é quase mitológica e que o mais correto seria pensar em Pequenas Áfricas. São todos esses espaços juntos que redefinem as expressões culturais africanas, muitas vezes vindas da Bahia, mas recriadas na cidade do Rio de Janeiro. O samba acompanhará os negros aonde forem, dando início a debates intermináveis como se o samba tem origem no morro ou na cidade, ou na Pequena África ou no Estácio. Indubitável é a importância das manifestações culturais afro-brasileiras e, neste caso, do samba, para a resistência e vitalidade do povo negro no Rio de Janeiro. Mesmo perseguido, ele fez de seus encontros religiosos e festivos um local de vida e existência plena e não apenas de sobrevivência, que hoje devem ser pensados como uma das maiores criações da história do país e ser motivo de orgulho de todos.

Nesta cidade marcada pela tentativa dos detentores do poder de extirpar as referências à herança africana, as diversas manifestações culturais das populações negras, exatamente aquelas que engendravam novos laços de sociabilidade e reforçavam convívios comunitários, eram sistematicamente perseguidas: a roda de samba, as festas religiosas, as maltas de capoeira, os blocos carnavalescos e batuques diversos (SIMAS, 2016, p. 3).

No entanto, o cenário da cidade, dos espaços e das manifestações da cultura popular é formado por mulheres e homens que se configuram como personagens da história fundamentais para o desenvolvimento do samba. São estas pessoas que nos cantam, encantam e contam as narrativas que podem nos ensinar sobre as relações étnico-raciais no Brasil. Dentre estas pessoas, fazemos o destaque para o protagonismo das mulheres que, no Rio de Janeiro das primeiras décadas do século XX, ficaram conhecidas como as Tias Baianas, ou as Tias do Samba, algumas delas mães de grandes sambistas como Tia Prisciliana, mãe de João da Baiana, e Tia Amélia, mãe de Donga, dois dos célebres nomes da história do samba.

Esse tratamento de tias para as mulheres que se salientavam aos olhos da comunidade pela maior experiência resultante da idade, ou pelo sucesso fi- 
nanceiro pessoal (o que as credenciava a proteger recém chegados, órfãos da vizinhança, e a promover festas em suas amplas casas), constituía uma sobrevivência cultural africana, onde na ordem familiar matrilinear o papel das irmãs é tão importante que os sobrinhos aparecem quase como filhos. Essa mesma estrutura familiar muito comum por toda a África, embora matizada conforme a região, entregava a casa da família ao controle total da mulher, o que viria a explicar a predominância dessas negras senhoras da comunidade baiana no Rio de Janeiro (TINHORÃO, 2010, p. 292).

Estas mulheres, desempenhando um papel de lideranças comunitárias a partir das posições que ocupavam no seio das religiões de matriz africana, "criaram redes de proteção social fundamentais para a comunidade negra" (SIMAS, 2016, p. 3). A casa da Tia Ciata e o seu terreiro, por exemplo, "eram santuários nagôs, mas também espaços de proteção social que abrigavam trabalhadores da estiva, pretos velhos, tocadores de tambor, inveterados boêmios e capoeiristas procurados pela polícia” (NETO, 2017, p.41). Foi na casa da Tia Ciata que as rodas de samba e choro do Rio de Janeiro, àquela época, puderam ocorrer com segurança.

Os terreiros religiosos, assim como as reuniões de samba, constituíram-se nos locais de maior resistência dos negros e negras, e essa resistência se deu muito a partir do fortalecimento dos laços entre eles. São essas relações sociais que engendram a própria atuação política da população negra em um país que não cansava de perseguir suas criações e produções, seus corpos e suas vidas, explorar seu trabalho.

Grande parte do povão carioca que se desloca do cais pra Cidade Nova, pro subúrbio e pra favela, predominantemente negro e mulato, também se organiza politicamente, em seu sentido extenso, a partir dos centros religiosos e das organizações festeiras. Assim, são essas negras, que ganham respeito por suas posições centrais no terreiro e por sua participação consequente nas principais atividades do grupo, que garantem a permanência das tradições africanas e as possibilidades de sua revitalização na vida mais ampla da cidade (MOURA, 1995, p. 135)

Para Neto (2017, p. 41), “a festa, portanto, era também uma fresta, espaço comunitário que subvertia a sujeição dos corpos à lógica produtivista do mercado e à normatização dos comportamentos exigidas pelos novos tempos, ditos civilizados".

Com estas compreensões de festa, encontro e resistência que se delineiam no universo do samba, ou seja, com parte do que este universo pode nos ensinar é que sugerimos a reflexão sobre o terceiro princípio explicitado no Parecer que nos tem servido de base, neste texto, para a Educação das Relações Étnico-raciais: “Ações educativas de combate ao racismo e a discriminações". Aliados aos encaminhamentos propostos por este princípio, o reconhecimento destas histórias de constituição do universo do samba nos instiga a questionar por que este ambiente festivo, de encontros, balanço do corpo ao som dos pandeiros não pode estar presente nos ambientes escolares e fazer, de maneira alegre e séria, parte das práticas pedagógicas e dos 
processos educativos ali desencadeados.

\section{Por uma educação sambista}

O princípio "Ações educativas de combate ao racismo e a discriminações" encaminha, em seus dois primeiros itens, para:

- a conexão dos objetivos, estratégias de ensino e atividades com a experiência de vida dos alunos e professores, valorizando aprendizagens vinculadas às suas relações com pessoas negras, brancas, mestiças, assim como as vinculadas às relações entre negros, indígenas e brancos no conjunto da sociedade; - a crítica pelos coordenadores pedagógicos, orientadores educacionais, professores, das representações dos negros e de outras minorias nos textos, materiais didáticos, bem como providências para corrigi-las[...](BRASIL, 2004, p.10).

Tais princípios, presentes na norma, nos levam à proposição da inserção das biografias e imagens das pessoas negras, bem como de suas produções simbólicas, materiais e imateriais, nos ambientes escolares. Notemos que pouca ou quase nenhuma referência às grandes personagens do universo do samba se fazem presentes nestes ambientes, sejam nos livros didáticos, em fotos nas paredes ou na menção de suas obras e contribuições à cultura brasileira. Dificilmente, em nossas experiências didáticas, observamos jovens estudantes universitários conseguirem associar, por exemplo, representativos nomes de sambistas como Pixinguinha, Clementina de Jesus, Dona Ivone Lara ou Cartola às suas respectivas fotos. A importância da presença das imagens dessas pessoas nas escolas se justifica pela necessária leitura de um corpo e uma estética negra que possibilitem a construção de uma identidade negra positiva, que façam o enfrentamento e a desconstrução de estereótipos racistas ou restritos às referencias do período da escravização dos povos negros.

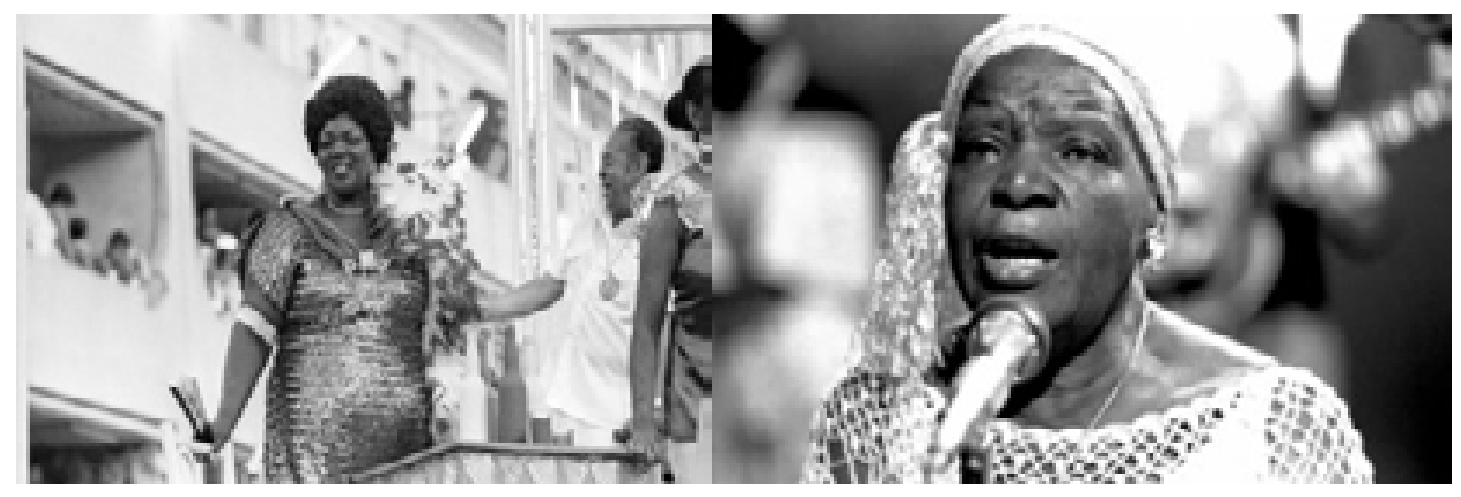

Figura 1- As sambistas Dona Ivone Lara e Clementina de Jesus

Para Gomes (2002, p.42),

se o corpo fala a respeito do nosso estar no mundo, a relação histórica do escravo com o corpo expressa muito mais do que a ideia de submissão, insis- 
tentemente pregada pela sociedade da época e que ecoa até hoje em nossos ouvidos. Será que a escola tem dado uma outra leitura a essa relação? Ou as crianças negras e brancas, quando estudam a questão racial, ainda participam da representação do corpo negro apenas como um corpo açoitado e acorrentado? Será que hoje, em pleno terceiro milênio, os livros didáticos e as discussões sobre a história do negro no Brasil realizadas pela escola destacam que o corpo negro, desde a época da escravidão, sempre foi um corpo contestador?

Ainda na perspectiva de desconstrução de estereótipos e de proposição de mudanças de posturas e atitudes para o desenvolvimento de práticas pedagógicas de combate ao racismo, entendemos como fundamental a abordagem da origem de diversas expressões e palavras racistas que, muito presentes em nossa sociedade, são enraizadas. Tais expressões têm, muitas vezes, a sua origem na crueldade e desumanização de determinados grupos étnicos, como indígenas, africanos e judeus, e o ocultamento desta história/origem se dá sob um pretenso caráter humorístico ou de descontração, sugerindo uma aproximação ou intimidade com o racismo que talvez o "abrandaria", amparado pelo mito da democracia racial e da ideia de mestiçagem. Entre tantas expressões que são reproduzidas sem as reflexões necessárias - e também por isso carecemos de uma Educação das Relações Étnico-raciais - está a "preto de alma branca”, cantada no samba intitulado "Identidade", de Jorge Aragão:

Elevador é quase um templo

Exemplo pra minar teu sono

Sai desse compromisso

Não vai no de serviço

Se o social tem dono, não vai...

Quem cede a vez não quer vitória

Somos herança da memória

Temos a cor da noite

Filhos de todo açoite

Fato real de nossa história

Se o preto de alma branca pra você

É o exemplo da dignidade

Não nos ajuda, só nos faz sofrer 
Nem resgata nossa identidade

(ARAGÃO, 1992).

Outra proposição de ação educativa que fazemos é a de promover o contato de professoras, professores e jovens estudantes com personalidades locais que vivem o mundo do samba, muitas vezes na própria comunidade escolar. Seja, por exemplo, com o convite a Mestras e Mestres de Escolas de Samba para irem à escola compartilhar os seus saberes, seja em visitas de estudantes às quadras e rodas de samba destes grupos. Outra possibilidade é a promoção de passeios aos locais que fazem parte desta história como, na cidade do Rio de Janeiro, à região da Pequena África, pois, de acordo com Silva (2009, p.46), para conhecermos, identificarmos e compreendermos as manifestações histórico culturais vinculadas a visões de mundo da população afro-brasileira, "há que conviver com pessoas negras que reconhecem seu pertencimento étnico-racial enraizado na África, há que frequentar territórios negros, há que buscar obras de autores e de outros profissionais negros".

Diante destas reflexões, resta-nos sugerir e desejar que muitas rodas de samba possam ser frequentadas pelas comunidades escolares e que muito samba seja vivido dentro das salas de aulas.

\section{Considerações}

Neste artigo, buscamos destacar alguns elementos do universo do samba como possibilidades para o desenvolvimento da Educação das Relações Étnico-raciais na escola e para a implementação da Lei 10.639/03, atentando para situar os conhecimentos provenientes deste universo como válidos, relevantes e de uma grandeza simbólica muitas vezes desprezados por uma hierarquização de saberes presente nas estruturas dos nossos sistemas de ensino, como herança colonial e eurocêntrica. No entanto, ressaltamos que para além das contribuições apontadas por este olhar, consideramos que muitos outros conhecimentos, em diversas outras áreas, podem e deveriam ser explorados para o ensino da história e cultura africana e afro-brasileira ${ }^{6}$. O que queremos evidenciar é a profusão de preciosidades que o universo do samba nos apresenta para este intento, cuja abundância não pode ser ignorada e enquanto o for deve ser questionada à luz das ideologias, desigualdades e estereótipos racistas presentes nas nossas sociedades.

Consideramos também que o universo do samba nos possibilita a dança, os passos e os versejos nos quintais e salões de todos os componentes curriculares da escola, ou seja, podem contribuir com a Educação das relações étnico-raciais em todas as áreas do conhecimento.

6 Neste sentido, é oportuno sugerir a visita aos trabalhos do senegalês Cheik Anta Diop que nos apresenta uma reconstrução da identidade africana a partir do estudo sócio histórico das contribuições e influências do continente africano para a história da humanidade. http://www.cheikhantadiop.net/ 


\section{REFERÊNCIAS}

ABREU, Marcelo de Paiva; LAGO, Luiz Aranha Correa. A economia brasileira no Império, 1822-1889. Texto para discussão 584. Departamento de economia PUC-Rio, 2010. Disponível em: < http://www.economia.puc-rio.br/mpabreu/pdf/Economia\%20no\%20Imp\%C3\%A9rio. pdf $>$ Acesso em 09 jul. 2018.

ARAGÃO, Jorge. Identidade. In: ARAGÃO, Jorge. Chorando estrelas. São Paulo: gravadora RGE, 1992. Faixa 10. Disco de Vinil.

BRASIL. Conselho Nacional de Educação. Parecer CNE/CP 3/2004. Diretrizes curriculares nacionais para a educação das relações étnico-raciais e para o ensino de história e cultura afro-brasileira e africana. Diário Oficial [da] República Federativa do Brasil, Poder Executivo, Brasília, DF, 19 mai. 2004. Disponível em: < http://portal.mec.gov.br/dmdocuments/ cnecp_003.pdf $>$ Acesso em 10 jul. 2018.

CANDEIA. Viver, In: CANDEIA. Candeia. Rio de Janeiro: Gravadora Equipe, 1970. Faixa 3. Disco de Vinil.

COSTA, Nelson Barros da. A produção do discurso lítero-musical brasileiro. 2001. Tese (Doutorado em Linguística). Programa de Pós-Graduação em Lingüística Aplicada e Estudos da Linguagem, Pontifícia Universidade Católica de São Paulo, São Paulo, 2001

FREIRE, Paulo. Pedagogia da esperança: um reencontro com a pedagogia do oprimido. Rio de Janeiro: Paz e Terra, 1997.

GOMES, Nilma Lino. Trajetórias escolares, corpo negro e cabelo crespo: reprodução de estereótipos ou ressignificação cultural? Revista Brasileira de Educação, n. 21, Set/Out/Nov/Dez, 2002.

GROSFOGUEL, Ramón. Racismo Epistémico, Islamofobia Epistémica y Ciencias Sociales Coloniales.Tabula Rasa, Bogotá, n. 14, p. 341-355, June 2011. Disponível em: <http://www. scielo.org.co/scielo.php?script=sci_arttext\&pid=S1794=24892011000100015-\&lng=en\&nrmiso >. Acesso em 05 ago. 2018.

FANON, Frantz. Em defesa da revolução africana. Lisboa: Livraria Sá da Costa Editora, 1980.

LOPES, Nei. Sambeabá: o samba que não se aprende na escola. Rio de Janeiro: Casa da Pala- 
vra, 2003.

LOPES, Nei; SIMAS, Luiz Antonio. Dicionário da história social do samba. Rio de Janeiro: Civilização Brasileira, 2017.

LOPES, Wallace; NOGUERA, Renato; MORAES, Marcelo. Introdução: Concentrando e esquentando os tamborins. Em: SILVA, Wallace Lopes. Sambo, logo penso. 1. ed. Rio de Janeiro: Hexis - Fundação Biblioteca Nacional, 2015.

MOURA, Roberto. Tia Ciata e a Pequena África no Rio de Janeiro. 2. ed. Rio de Janeiro: Secretaria Municipal de Cultura, Divisão de Editoração, 1995.

MUSSA, Alberto. Apresentação. In: LOPES, Nei; SIMAS, Luiz Antonio. Dicionário da história social do samba. Rio de Janeiro: Civilização Brasileira, 2017.

NETO, Lira. Uma história do samba. São Paulo: Companhia das Letras, 2017.

ROSA, Noel; VADICO. Feitio de oração. 1933. In: Coral de Ouro Preto. São Paulo: Gravadora Odeon. 1961. Disco de Vinil.

SILVA, Lidiane Moreira e. Mar de memórias na poesia de Agostinho Neto. Revista Moara, n. 38, p. 113-125, jul./dez., 2012.

SILVA, Wallace Lopes; NOGUERA, Renato. Praças negras: territórios, rizomas e multiplicidade nas margens da Pequena Africa de Tia Ciata. Em: SILVA, Wallace Lopes. Sambo, logo penso. 1. ed. Rio de Janeiro: Hexis - Fundação Biblioteca Nacional, 2015.

SILVA, Petronilha Beatriz Gonçalvez. Aprender, ensinar e relações Aprender, ensinar e relações étnico-raciais no Brasil étnico-raciais no Brasil. Educação. Porto Alegre/RS, ano XXX, n. 3 (63), p. 489-506, set./dez 2007.

Disponível em: http://revistaseletronicas.pucrs.br/ojs/index.php/faced/article/view/2745. Acesso em 01 de jul. 2018.

A palavra é... Africanidades. Presença pedagógica, Belo Horizonte, v. 15, n. 86, p. 4247, mar/abr. 2009.

SIMAS, Luis Antônio. Dos arredores da Praça Onze aos terreiros de Oswaldo Cruz: uma cidade de Pequenas Áfricas. Revista Z cultural. Ano XI, 01. 2016. 
TINHORÃO, José Ramos. História social da música popular brasileira. 2. ed. São Paulo: Editora 34, 2010.

VILA, Luiz Carlos da; RODOLPHO; JONAS. Kizomba, festa das raças. 1988. Disponível em: $<$ https://www.youtube.com/watch?v=pYFemPjfcF8 $>$ Acesso em: 01 jul. 2018. 